\title{
Wabu Gadun Bulmba Gurriny Mukanji Centre: A Case Study of Intercultural Design Practice
}

\author{
Shaneen Fantin \\ Director, People Oriented Design, Cairns \& James Cook University \\ GudjuGudju Fourmile \\ Gimuy Walubara Yidinji Elder \& \\ Director Indigenous Construction and Training Company and Abriculture, Cairns
}

\section{Introduction: the story behind working together}

\begin{abstract}
Tn 2011 GudjuGudju ${ }^{1}$ Fourmile, elder of the Gimuy Walubara Yidinij people, asked me to 1 work with him, as an architect, on the conceptual design for a facility for Indigenous people with acquired brain injury. I have been working with Indigenous people on projects since 1995, but this is the first time that I have worked as a sub-consultant to an Indigenous Design Manager. This is a critical change from being engaged by non-Indigenous organisations, or the Government, to provide services to or with Indigenous people. Being directly instructed and lead by Indigenous Construction and Training Company (ICTC) and guided by the Fourmile family has lead me to an experience of intercultural design practice; an experience full of new learning, excitement and challenges, patience and respect.
\end{abstract}

The term intercultural was coined in the mid-1990s in non-Indigenous communication and educational writing (Bryam and Guilherme 2010:4). Its conscious application to architecture and design writing in Australia is relatively recent (Radovic 2004, Martin and Casault 2005, Fantin and Greenop 2009). A common element between the communication/ education literature and design literature are references back to the studies of Edward T Hall's (1966) The Hidden Dimension in non-verbal and spatial communication.

The story that is told in this paper is mainly written from the perspective of myself, the architect. My co-author and guide, GudjuGudju Fourmile, has reviewed the paper and added important insights. He has also authorised it for distribution. The story describes the architectural design process for this project, and some of the interpersonal nuances and challenges along the way. I asked GudjuGudju if I could write about this project because I believe it demonstrates innovation in design practice and in the incorporation of Indigenous knowledge and identity into architecture.

I have purposefully written the paper as part description and narrative with interwoven references to historical and theoretical examples, because this is the most effective way to tell the story. It is the way it should be told from an intercultural perspective and from a Yidinji

\footnotetext{
${ }^{1}$ The name GudjuGudju is used in this paper as a means of respect to Mr Fourmile whose uncle (who shared the same non-indigenous name) passed away shortly after writing this paper.
} 
perspective (Bessarab and Ng'andu 2010). Through experiencing the paper in this way, you will engage in the participatory process of intercultural practice. A process that is fluid, based on experience and phenomenology, listening, feeling and paying attention to small nuances and non-verbal cues.

The co-author for this paper is GudjuGudju Fourmile of the Gimuy Walubara Yidinji Nation. Mr Fourmile's ancestry comes from the Yidinji Nation and his great grandfather was a Nalan (Leader). He was given a 'King Plate' by the British when they first arrived and was known as Yie-Nie the King of Cairns. His clan's estate runs from Mackey Creek north of Gordonvale to the Barron River. Mr Fourmile is an Indigenous leader, ceremonial leader, artist, educator, project manager and electrician.

As the primary author, I come from third and fifth generation migrant families and we have been living and farming at Mt Peter between Edmonton and Gordonvale since 1927. I am an architect, educator and project manager. My identity is also anchored in far north Queensland. It is anchored in a European migrant history, and Italian sugar-cane farming history.

GudjuGudju and I are from different cultural backgrounds and have different genders. GudjuGudju's family has thousands of years of history, memory and place-making in north Queensland. My family has 85 years of local memory and place making. We have come together, with a group of other committed people ${ }^{2}$, to work on a project through a shared passion of design, country and landscape and social justice. To do this we made a conscious decision to engage in an intercultural design process.

I believe the beginning of stories is very important, because it provides an historical context for the journey or experience. The beginning of this story, from my perspective, is when I met GudjuGudju and his partner, Jenny. At the time they were my neighbours and I wanted to pay my respect to GudjuGudju as an elder of the traditional owner family of the country that I grew up on. I was also acutely aware that I knew little about north Queensland's Indigenous cultural landscape. I had travelled and worked in many places in Australia and knew something of the beauty of ancestors and stories in the country from other places, particularly Arnhem Land, but not from here; not from the place where I grew up. I felt bereft because the history of Queensland is so raw that I knew why I didn't know. It is a history of genocide and discrimination. The Indigenous cultural knowledge that exists is not regularly advertised or published. Some knowledge and histories have been published by anthropologists and other researchers/academics, but the issue of research and publication is a delicate issue of intercultural studies.

Much local Indigenous knowledge is kept safe and secret with the families who know it and own it. For many non-indigenous people, if something is not recorded or written down there is a misplaced assumption that it is not known. Working with ICTC and the Fourmile family has brought me to understand that there is an extraordinary amount of Indigenous cultural history alive in north Queensland that it exists in oral tradition and family lineages. And, if it were written and published in books and on the internet, then it is open to interpretation, bastardisation and misuse by others.

\footnotetext{
${ }^{2}$ People Oriented Design, Indij Design, Belinda Allwood Architect, Synapse, Abriculture
} 
I met with GudjuGudju and his family and started a conversation about families and Country ${ }^{3}$, gardening and design. And we found a common place where comfortable and easy discussion about culturally responsive design, building things, about trees and plants, local landscapes and families could flourish. This is what in the non-indigenous literature is called the intercultural space (Merlan 2005, Radovic 2004, Martin and Casault 2005). This is a space for listening, sharing, learning and attempting to understand the world through someone else's eyes. In this space also lies much uncertainty, questioning of values, challenge of cultural assumptions and need for self-reflection. It is a meandering and exploratory space, where it is easy to make mistakes and create confusion.

It was around this time that GudjuGudju (as Director of ICTC) asked me if I had time to assist on a project as an architect for a new kind of health facility. We went to a meeting together with Sam Backo (the other Director of ICTC) and the client (Synapse - the Acquired Brain Injury Association of Queensland) and we talked about acquired brain injury, culturally appropriate design, mental illness, caring for others, Indigenous incarceration, models of rehabilitation, the importance of cultural and social support and being in a non-institutional setting. We spoke of many sad and happy experiences. We talked about our families and our experiences of caring, and during the tea break I was overwhelmed with emotion. This meeting enabled us to understand what was needed for the project, and why and whom it was being created for. It also solidified our commitment to the project.

Shortly after the meeting, we worked together as a small team, GudjuGudju, Sam, Jenny, myself and Synapse to submit a concept design to accompany a grant submission for the project. Several months later the grant had been approved and the project was real.

The two key elements that I believe make working on Indigenous design projects confronting and difficult for all participants are: 1.the challenging of cultural and social assumptions; and 2. the unavoidable presence of emotions and feelings. The non-indigenous realm of project management, design and construction is usually focussed on technical detail and strict timeframes. And those who work in it are generally not very well trained in understanding or managing emotions and feelings but well versed in time and budget management. However, processing and handling strong emotions with some grace is essential to effective intercultural design practice. Challenging cultural assumptions about project management and business are a key part of the method that ICTC chose because we were trying to do business in a way that allowed for Indigenous decision making processes. As we attempted to bring competing priorities together in meetings it created conflict and stress, and we regularly had to explain and reiterate the Indigenous priorities for the project while simultaneously meeting project management milestones.

This particular project journey has been full of emotions and challenges. Talking about Country and family is often full of emotion; coupled with discussing illness, disability and caring, has created a project that struck people to their core. It also solidified the Design Team at critical moments because we were unified through emotional commitment to the project. One such critical moment was when GudjuGudju suffered a stroke in the middle of the project. It was as dramatic and destabilising as it sounds. We received a call late one afternoon that GudjuGudju was in hospital. He was bedridden for a number of weeks and lost strength and dexterity in the left side of his body. While GudjuGudju was in rehabilitation, the day-to-day management of the Design Team was carried out by ICTC's Alex Woodcock

\footnotetext{
${ }^{3}$ Country in this context refers to the Indigenous meaning and use of the term country, as homeland
} 
and Sam Backo. Alex, Sam and GudjuGudju have very different management styles, but the team adapted and adjusted and Alex lead the team from sketch design stage through the majority of design development.

When GudjuGudju returned to the project it was with a personal perspective of acquired brain injury, models of care and rehabilitation. He was then able to bring this experience to the project.

\section{The design process: constraints and outcomes}

To progress the project we built a team of like-minded colleagues with a range of skills. Approximately half of the professional services on the project have been provided by Indigenous people (architects, ecologists, design managers, trainers). The project has a traditional owner and traditional ecologist stakeholder group, with whom we meet at key stages to inform and support the design process. We were also given some project stakeholders who were chosen by the client, and we have attempted to bring everyone into the intercultural design space. Everyone came to the project with some preconceived notions of culture, design, education and business. In each discussion and meeting (inside or outside the design team), different stakeholders were challenged on their preconceptions of management, design process, knowledge ownership, and communication protocols. When I thought the process was not respectful of ICTC's intended direction, I would first raise my observation or assumption with ICTC and then, with their authorisation, I would explain the issue to my team. In other scenarios, ICTC would correct me on my assumptions and provide guidance on their preferred way of running the project. This part of the work is continuous, it is about listening, questioning and learning, and everyone is learning at a different pace. As Radovic (2004:180) states, 'The shattering of one's foundations is what all research, and in particular what which operates in the intercultural arena, needs'.

The design methodology was not explicitly discussed when the project started. What was discussed over a series of meetings was how the project was to be managed, by whom, with which other stakeholders and how, and what communication protocols should be followed. From the beginning ICTC were trying to incorporate Indigenous ways of doing business into the project management methodology. This was characterised by requiring a point of recognition and respect for ICTC as Indigenous Managers and as representatives of the traditional owner group for the proposed site for the facility. This manifested in a number of activities and practices, which initially challenged some of the parties on the project, but eventually became incorporated into the project process. Such as,

- Acknowledgement of traditional owners at every meeting

- Clear communication protocols that gave ICTC control and veto over design decisions

- Allowance in project timeframes for meetings with traditional owner design and ecology groups and for cultural family business such as 'sorry business'.

- Being respectful during meetings and allowing everyone space and time to talk without being interrupted or spoken over

Creating an Indigenous-lead design and management process was part of our intended methodology, but pragmatically it was hard to achieve given that the funder was a Government department with a non-Indigenous project management methodology including GANNT charts, conference room settings and delivery milestones. The process that resulted 
was more flexible and discursive than others I have worked on, but it was still a nonIndigenous framework in which the Indigenous design team danced, weaved and negotiated to be able to apply a more iterative process in parallel. GudjuGudju describes the design process that we developed as being non-Indigenous architectural traditions injected or affected by Indigenous beliefs and practices. Martin and Casault (2005:5) refer to this in their work in Canada with the Innu, 'The Innu are continually fashioning a way of being in the world that builds on the past while simultaneously resisting and embracing white Western values'. This reflects our own process in which we often had meetings to discuss how to work within and around the structure imposed upon us and still achieve a design and process that responded to Indigenous priorities and ways of living.

\section{The Importance of Naming}

The project was named the Wabu Gadun Bulmba Gurriny Mukanji Centre (otherwise known as Gurriny) which means 'Come share the good heart of the healing home' in Yidin. The Fourmile family named the project a little way into the design process. Naming of the project and its components has been a very important. Each building design that was developed was given a Yidin name. Western drawing convention gives buildings generic names and numbers. There is no emotion or spirit in the plan description of the South Elevation SD 1.03. There is emotion in calling a living unit a Boori or a Bulmba. The Bulmba is the name of the living unit that evolved as the preferred option within the Gurriny Centre. Bulmba means place, shelter, camp or house in Yidin. It is a broad term for a place of dwelling. In Arnhem Land in the late 1990s I learnt that when a building or a place is named by a traditional owner it is significant and creates a relationship with the place. It is a recalling of ownership and connection to an existing ancestral history and place. As Williams (1986:42) and Tamasari (2002:16) note, for something to be named implies a notion of belonging to that group and country: naming brings into being. In discussions with GudjuGudju (PC 21.06.13) he describes this as 'bringing the name of the thing out' and that it makes the old people happy.

Gurriny Centre aims to create a rehabilitative environment for people with acquired brain injury through individual program services in a residential setting where the landscape and building designs are integral to each other. The place consists of eight individual Bulmba (living units) clustered around a central facility. The site is a generous rural location on Yidinji land. The design of the buildings and the landscape was carried out with Yidinji design and ecology groups and individuals over a number of meetings where ideas were formed, developed and refined. I concur with Martin and Casault (2004:16) when they state 'Of utmost importance are the skills of listening, observing, and drawing, and of questioning what seems taken for granted by oneself and the "client", for it is with these that one can make visible and materialize the essential'.

What does to 'materialize the essential' mean? In architectural design it means to draw out and refine the essence of something; to find the key purpose and spirit of something. This is precisely what we attempted to do with a range of stakeholders; with the client on the model of health care, with the Yidinji rational owners in the design workshops, with the Design Managers on their vision for Indigenous management of the project. Our role as the design team is then to balance and unify these essential components and make a Yidinji place for people with acquired brain injury to rest and heal.

\section{Approach to Model of Care, Planning and Building Code Constraints:}


How is all this made evident in the design? Gurriny has been designed with careful consideration for the philosophy and model of care planned by the client. The health provider client is Synapse (formerly Brain Injury Association of Queensland), The facility is to provide transitional care for people with acquired brain injury in an environment that is supportive but that also encourages independence and rehabilitation specific to the needs of each person. Gurriny consists of eight Bulmba (living units), one central building, and extensive native gardens and landscaped outdoor spaces. The centre is not specifically for people of Aboriginal and Torres Strait Islander decent, however it is expected that the majority of clients will be Indigenous because of the cohort of people in north Queensland with acquired brain injury.

The buildings are carefully arranged on the site within a native rehabilitative garden (or 'Abriculture' ${ }^{4}$ landscape). The gardens include vegetable gardens, bush foods, native plants for manufacturing, a freshwater therapy pool and a native seasonal plant-clock. The freshwater, hydrotherapy pool is adjacent to the central facility and is fully accessible by wheelchairs. The maintenance and use of the gardens are intended to be part of the rehabilitation of the people receiving care: rather than physiotherapy with tools in a nonindigenous sense, the intention is to create a landscape that can be used as the tools for physiotherapy. For example, instead of putting peas in a jar to improve fine motor function, the clients should be able to sort lily pillys or, pick herbs from the garden or, strip Yakal (pandanus) leaves to weave a basket (and be reminded of home and country at the same time).

The central facility has been designed at a domestic scale to be non-institutional and welcoming. A number of spaces within the central facility are multi-purpose and open to large verandahs, which maximises connections with the gardens and promotes natural ventilation. From the street, the central facility will be invisible as there is a $60 \mathrm{~m}$ landscape buffer proposed to the neighbouring property. All the Bulmba are within 30m of the central facility and the high dependency Bulmba are within $10 \mathrm{~m}$. This enables easy and immediate access between the buildings and maintains visual surveillance of each Bulmba from the staff unit. Each living unit is connected to the central facility with an emergency call system and sealed pathways. The Fourmile family note that because the design brief had to focus on the needs of the health provider, and the working time frames were compressed, that the design of the Central Facility is not as responsive to Indigenous needs as the design of the Bulmba.

All of the buildings on the site have been designed and arranged to passive climatic design principles for the tropics. They capture the local breezes, shield from the storms and have extensive shading and overhangs to protect from the sun. The central facility will capture rainwater to irrigate the vegetable gardens. The sewerage system for the facility is contained on site adding providing irrigation to some of the lawn areas. The design of Gurriny Centre has been classified as a 9a Health Care Building under the Building Code of Australia. It exceeds the Australian Standard 1428 - Design for Access and Mobility, and 90\% of the complex meets the platinum level of the Liveable Housing Design Guidelines. The building has also been designed to achieve a six star commercial energy assessment rating under the Building Code of Australia.

\section{Approach to Design for Indigenous Clients and Respect for Yidinji Land:}

\footnotetext{
4 'Abriculture' is the name of a company and way of working developed by Seith Fourmile and Jenny Lynch to develop local Indigenous food forests and gardens.
} 
The proposed design is anchored in the land and country in which it is based. The current site is on Yidinji land, and it aims to recognise the Yidinji and its Indigenous clients through a number of landscape and design features. Early in the process, design workshops were held with the Yidinji to discuss how Indigenous culture could be expressed in the design without causing offence or confusion to non-Yidinji Indigenous clients and users of the facility. There is a design engagement methodology that I (Fantin 2003b) developed in the late 1990s that was used as a framework to start conversations around culture and design. The method starts with a presentation on design and architecture in International Indigenous environments and then moves to discussions on identity represented in stories, art and history, the site and the country around the site. It also includes discussions about social and cultural norms and behaviours. The process aims to find consensus on what and how the Yidinji wanted their cultural identity recognised in the design. This process occurred over a series of meetings in which design ideas were developed and discussed with ICTC prior to discussing them with the traditional owner group.

A summary of Indigenous and Yidinji features of the design:

- Incorporation of references to the rainforest cross-boomerang, the Wangul, as the anchoring design element for the orientation of the buildings and landscape. The crossboomerang was the symbol chosen by the Yidinji elders as appropriate for the project and place. It was seen as specific to the rainforest of north Queensland, but not a totemic ancestor featured in local histories that would cause any angst or confusion with another group.

- The orientation and layout of the facility responds to the cultural and scenic views of the site. The axis of the facility is the axis of the Wangul and aligns with views to Bunda Djarragan (the Pyramid) to the south, Bunda Mundii Ghunji White Rock to the north and Bunda Meringi (Mt Peter) to the west; all significant Yidinji places.

- The Bulmba form was inspired by traditional Aboriginal rainforest architecture of the region. Each Bulmba has an outdoor barbeque area and healing herb garden. The Bulmba have curved internal corners to minimise places for bad spirits to harbour. The Bulmba are designed to be constructed of timber to feel natural and warm.

- The facility and the buildings have been given names in Yidin, anchoring them to the place and the people whose land the facility sits on.

- The roof of the central facility has a number of planes, and the main plane has a slight twist. This is a subtle reference to leaves and traditional Yidinji water carriers from the region.

- The spatial organisation of the buildings and rooms within buildings provides privacy but also enables people to pay respect to various family members including 'poison cousins' (those in avoidance relationships. See Fantin 2003). Most spaces have multiple entries and exits so that people can move subtly away from one another if needed.

- The landscape design is extensive and intricate and includes native bush food and medicinal plants, vegetable gardens, fruit trees, private gardens for each unit and a native seasonal plant-clock. Each plant has been identified using its Yidin and scientific botanical name.

- The seasonal plant-clock is at the south of the facility and includes a selection of species that flower and/or fruit at different times of the year. The seasonal plant-clock allows clients to connect with other environmental triggers in the surrounding landscape. 
The design workshops and meetings were a two-way learning environment. To develop appropriate design ideas the Yidinji had to educate the architectural team about themselves and their belief system. And to understand how buildings are designed, documented and created, the architectural team had to share their knowledge and experiences of sustainable and responsive design and construction. I believe the innovation in this particular intercultural design process has come through the brokerage and facilitation of ideas from one cultural and social domain to another. Positive two-way education needs a particular environment to flourish. It needs:

- Respect for existing practices and beliefs;

- Understanding and recognition of existing traditions, history and experience;

- Willingness to work together, to listen, to apply, to refine the thinking and the work as it progresses.

This sounds obvious and easy to achieve, but in reality it is not. We are all products of, and servants to the cultural and social paradigm we were raised and exist within, and unless we are brave enough to challenge what we think we know, we reduce our capacity for learning. As Martin and Casault (2004: p?) point out ' ... when I was educated as an architect I was educated in non-indigenous methods of expert defence and justification, rather than collaboration'. We should remember that the word expert comes from 'experience', and it is this that we should bring to a collaborative design environment - not judgement.

\section{Reflection and Learning}

In July 2013, The Gurriny project was being prepared for development application to Cairns Regional Council. The Design Team worked day and night to complete the developed design drawings, checking and editing, tweaking and fine tuning. We are now waiting to hear if the project will proceed in its current location. It has had to overcome a vast array of obstacles and objections and we are hopeful that it will continue through to construction.

Eighteen months after the project had commenced, I asked GudjuGudju if he thought this project was an example of equitable intercultural design practice. He was thoughtful in his response, paused and said, not really because so many of the constraints for the project were non-Indigenous in their essence. I was not deflated at this comment, but curious. His criticism is not of the process we attempted to apply, but of the context we are working in. He reminded me that this project is essentially a health facility (with a non-Indigenous model of care) in a colonised country with proposed site on Indigenous land. Attempts at intercultural design practice in a country where the original inhabitants have been removed from their land, have been marginalised and are not consistently recognised in legislation or cultural and social practice is difficult. The place at which we commence design negotiations is not equal, because the framework for the majority of the constraints is non-Indigenous. We are not entering into the intercultural design space at the same level, so how can equity be achieved?

Radovic (2005:178) says of the Urban Design Studios he has run in south-east Asia ‘ Design... was just the vehicle for achieving some broader design agendas. The key objectives of the...studios were to meet...the difference, to discover the depth of the otherness and to shake off disciplinary self-confidence and cultural prejudice'. In principle this is what we attempted to do. Our design team contained a number of parties who had little experience at 
working collaboratively. Everyone was challenged to reassess what they thought they knew about design, management and models of health care, and to bring competing constraints together. Toward the end of the process we learnt that rather than eliminate alternatives, we had to find the most suitable ideas in each component and combine them in a multi-faceted solution (and as discussed by Radovic 2005:177); this is also true for the process we participated in. However, in Radovic's writing there is minimal reference to the underlying historic and legislative context in which the projects occurred. We must always be mindful in intercultural design practice in Australia of the dominant constraints of program, legislation, land tenure and history that already exist.

In most design processes there are those constraints that cannot be negotiated because they are physical or legislated and then there are competing constraints, of which everything else consists. This project has a combination of competing and diverse Indigenous and nonIndigenous imperatives that were regularly being tested against each other for priority. However, the majority of constraints that could not be negotiated were non-Indigenous. The Indigenous imperatives were allowed to permeate into the design because of the understanding and leadership of the Chief Executive Officer of Synapse and ICTC, and the commitment of the architectural and Abriculture teams. Without key advocates and guides in these positions the project would have been considerably more "main stream". It is one thing to acknowledge Indigenous identity in design through consultation, cursory references in the built environment, colour scheme and motifs. It is entirely something else to be on a project with Indigenous leadership in which non-Indigenous management and design practice is being challenged and a new practice model is evolving and being tested.

In 2003, I authored an article 'Aboriginal Identities in Architecture' (Fantin 2003a). The article investigated what constitutes Indigenous architecture, making an argument that Indigenous leadership in design activities and place-making are more relevant to creating Indigenous architecture than embedding abstract imagery of Indigenous ancestors in built form. At the beginning of this project I was uncertain where or how it would progress. And much of the generation of ideas about the design has been more like an argumentative fermenting process, rather than the artist 'light bulb' moment. The task is one of observation, feeling and translation, negotiation, with continual reflection and fine tuning along the way. However, I continue to believe that to create Indigenous architecture, Indigenous leadership, involvement and engagement in the process should be implicit. It should be "how we do business” on Indigenous projects, not an additional consideration.

\section{Acknowledgments}

There are many people who have contributed and collaborated in this intercultural design space. I would like to acknowledge the contributions of the client's representatives: Rochelle Stair, Jennifer Cullen and Jo Priestly of Synapse. The leadership and design guidance of GudjuGudju Fourmile (ICTC \& Abriculture), Sam Backo (ICTC) and Alex Woodcock (ICTC). Dedicated contributors to the design process: Jenny Lynch (Abriculture), the Yidiniji Traditional Owner and Ecology Groups, the Fourmile extended family, Andrew and Francois Lane (Indij design), Belinda Allwood (BJ Allwood Architects), Suzan Quigg (Landscape Design), Hutchinsons Building Contractors, AECOM civil and structural design team, Davis Langdon project management and cost management, WPS Lincoln Scott electrical design, 
and $\mathrm{H} 2 \mathrm{O}$ hydraulic consultants. And last, but not at all least, editorial and writing guidance of [soon to be] Dr Kelly Greenop.

\section{Works Cited}

Bessarab, D and Ng' andu, B (2010) Yarning About Yarning as a Legitimate Method in Indigenous Research in International Journal of Critical Indigenous Studies, Queensland University of Technology, Brisbane. Vol 3. No. 1

Bryam, M and Guilherme, M (2010). Intercultural Education and Intercultural Communication: Tracing the Relationship. In Becoming Intercultural: Inside and Outside the Classroom. Tsai, Y and Houghton, S (eds). Cambridge Scholars Publishing. UK. Chapter 1. (4-18).

Fantin S., (2002) Recognising Aboriginal architecture from northeast Arnhem Land: The 'ancestral aesthetic in Yolngu dwellings and ceremonial structures, in. Additions SAHANZ Conference Proceedings, Brisbane, Oct 4-7.

(2003a) Aboriginal Identities in Architecture in Architecture Australia Sept/Oct (2003b) Housing Aboriginal Culture in Northeast Arnhem Land. PhD Thesis, Aboriginal Environments Research Centre, University of Queensland, Brisbane.

Fantin, S and Greenop, K (2009). Sorcery and spirits: Intercultural housing and place in Aboriginal Australia. In: Julia Gatley, Cultural Crossroads: Proceedings of the 26th International SAHANZ Conference. Cultural Crossroads: 26th International Conference of the Society of Architectural Historians, Australia and New Zealand, Auckland, New Zealand, (1-13). 2-5 July.

Hall, E T. (1966) The Hidden Dimension, Doubleday \& Company Inc. New York.

Lawrence, RJ. (1989) Translating Anthropological Concepts into Architectural Practice. in Setha, M \& Chambers, E (eds) Housing, Culture \& Design. A Comparative Perspective. University of Pennsylvania Press, Philadelphia.

Lochert, M. (1997) Mediating Aboriginal Architecture in Transition, Issue 54-55, pp 8-19.

Martin, T and Casault, A (2005) Thinking the Other: Towards Cultural Diversity in Architecture. Journal of Architectural Education (1984-) Vol. 59, No. 1 (Sept). pp 316. Wiley on behalf of the Association of Collegiate Schools of Architecture, Inc.

Memmott, P. (2007) Gunyah, Goondie \& Wurley. The Aboriginal Architecture of Australia, St Lucia: University Qld Press,.

Neidjie, Bill (1989). Taylor, Keith, ed. Story about Feeling. Broome, W.A: Magabala Books.

Radovic, D (2004) Towards culturally responsive and responsible teaching of urban design. In [state editors here] Urban Design International, Palgrave Macmillan Ltd Vol 9, pp175-186. 
etropic 13.1 (2014): Leadership in Indigenous Research Special Issue | 34

Tamisari, F (2002) Names and Naming: Speaking Forms into Place in Hercus, L., Hodges, F., and Finlayson, J. (eds) The Land is a Map: Place names of Indigenous Origin in Australia, Pacific Linguistics Series pp87-102.

Williams, Nancy, (1986) The Yolngu and Their Land: a system of land tenure and the fight for its recognition. Canberra: Australian Institute of Aboriginal Studies 